\title{
Load Forecasting of Distributed Energy in Industrial Park and Its Investment Linkage Analysis
}

\author{
Shuo Yin ${ }^{1}$, Yao Lu ${ }^{1}$, Shiqian Wang ${ }^{1}$, Zhe Chai ${ }^{1}$, Man Jin ${ }^{1}$, Xing Chen ${ }^{1,}{ }^{*}$, Jie $\mathrm{Hu}^{2}$ \\ ${ }^{1}$ State Grid Henan Economic Research Institute, Zhengzhou, China \\ ${ }^{2}$ Ohio State University, USA
}

\begin{abstract}
Power grid enterprises are changing their function orientation and profit model under the background of new power system reform. Vector autoregressive model used for industrial park to forecast load of distributed energy is created in this paper, which provides the data to the analysis of the investment environment of grid enterprises. We excavate the core influencing factors of grid investment in incremental distribution parks based on the linkage of grid investment influencing factors in system dynamics.
\end{abstract}

Keywords: Park; Incremental distribution; Investment impact; Linkage.

\section{Preface}

The "No. 9 Document" clearly puts forward the requirements of steadily promoting the reform of the electricity sales side, promoting the construction and development of distribution networks, exploring effective ways for social capital to invest in the electricity distribution business, gradually liberalizing the investment business of incremental electricity distribution, and improving the efficiency of electricity distribution operations, and encouraging the development of electricity distribution and sales business by means of mixed ownership. Load forecasting of energy and its linkage investment are key ways to provide scientific basis for optimum resources matching and raising productivity. In the short term, the objectives of this electricity reform are clear, aiming to build on the achievements of the previous round of electricity reform, consolidate and strengthen the effectiveness of the reform, further promote the opening up of the electricity sales side, open up the field of investment in incremental electricity distribution, attract social capital injection, strengthen competition in the electricity sales market, reasonably optimise resources on the distribution side, improve efficiency, while accounting for transmission and distribution prices, change the profitability model of grid enterprises, strengthen government regulation in those segments with a strong natural monopoly in transmission and distribution The Government should also allow the power generation side to participate directly in the competition on the electricity sales side, conduct direct power purchase with large users, establish a unified trading centre, improve the electricity trading system, and realise the marketisation of electricity mainly in pilot areas, so as to provide experience and lessons for the future marketisation reform of the distribution and sales side and lead the way for future reform.

\section{Load forecasting of distributed energy in industrial park based on vector autoregressive model}

Based on the historical data of distributed electricity power $\left\{l_{e}(t)\right\}$, gas energy $\left\{l_{g}(t)\right\}$, cold energy $\left\{l_{c}(t)\right\}$ and heat energy $\left\{l_{h}(t)\right\}$ in industrial park, vector autoregressive model (VAR) can be used to describe and simulate their load, of which the autoregressive model order should be decided in accordance with minimum information criterion (AIC). Load forecasting vector autoregressive model has the advantage of reflecting dynamic persistence characteristics, which means it can reveal the relationship among different forms of energy from the historical data and accurately forecast distributed energy load in the future.

(1) Vector autoregressive model of electricity power In the vector autoregressive model of hybrid forecasting electricity power, of which the autoregressive model order is assumed to be 2, electricity power and cold energy are assumed to be endogenous variables, while gas and heat energy are assumed to be exogenous variables. Electricity power can be expressed as:

$$
l_{e}(t)=\left(\begin{array}{ll}
A_{1} & A_{2}
\end{array}\right)\left(\begin{array}{l}
L_{e} \\
L_{c}
\end{array}\right)+\left(\begin{array}{ll}
B_{1} & B_{2}
\end{array}\right)\left(\begin{array}{l}
l_{g}(t) \\
l_{h}(t)
\end{array}\right)+\varepsilon(t),
$$

where $L_{e}$ can be expressed as $\left[l_{e}(t-1), l_{e}(t-\right.$ $\left.2), l_{e}(t-3)\right]^{T}$ and $L_{c}$ has the expression of $\left[l_{c}(t-\right.$ 1), $\left.l_{c}(t-2), l_{c}(t-3)\right]^{T}$.

(2) Vector autoregressive model of gas energy

In the vector autoregressive model of hybrid forecasting gas energy, of which during the autoregressive model

\footnotetext{
* Corresponding author: chenxing@ha.sgec.com.cn
} 
order from 1 to threshold value, gas and heat energy are assumed to be endogenous variables, while electricity power and cold energy are assumed to be exogenous variables; during the autoregressive model order above threshold value, gas and heat energy are assumed to be endogenous variables, while only electricity power is assumed to be exogenous variables. Gas energy can be expressed as:

$$
l_{g}(t)=\left\{\begin{array}{ll}
\left(\begin{array}{ll}
A_{1} & \left.A_{2}\right)
\end{array}\right)\left(\begin{array}{l}
L_{g} \\
L_{h}
\end{array}\right)+\left(\begin{array}{ll}
B_{1} & \left.B_{2}\right)
\end{array}\right)\left(\begin{array}{l}
l_{e}(t) \\
l_{c}(t)
\end{array}\right)+\varepsilon(t), 1 \leq t \leq 21, t=30 \\
\left(\begin{array}{ll}
A_{1} & \left.A_{2}\right)
\end{array}\right)\left(\begin{array}{l}
L_{g}^{\prime} \\
L_{h}^{\prime}
\end{array}\right)+B_{l} l_{c}(t)+\varepsilon(t), 22 \leq t \leq 29
\end{array},\right.
$$

(3) Vector autoregressive model of cold energy In the vector autoregressive model of hybrid forecasting cold energy, of which during the autoregressive model order from 1 to threshold value, gas and heat energy are assumed to be endogenous variables, while electricity power and cold energy are assumed to be exogenous variables; during the autoregressive model order above threshold value, gas and heat energy are assumed to be endogenous variables. Cold energy can be expressed as:

$$
l_{c}(t)=\left\{\begin{array}{l}
\left(\begin{array}{ll}
A_{1} & A_{2}
\end{array}\right)\left(\begin{array}{l}
L_{e} \\
L_{c}
\end{array}\right)+\left(\begin{array}{ll}
B_{1} & B_{2}
\end{array}\right)\left(\begin{array}{l}
l_{g}(t) \\
l_{h}(t)
\end{array}\right)+\varepsilon(t) \quad, 1 \leq t \leq 21, t=30 \\
\left(\begin{array}{ll}
A_{1} & A_{2}
\end{array}\right)\left(\begin{array}{l}
L_{e}^{\prime} \\
L_{c}^{\prime}
\end{array}\right), 22 \leq t \leq 29
\end{array},\right.
$$

(4) Vector autoregressive model of heat energy

In the vector autoregressive model of hybrid forecasting heat energy, of which during the autoregressive model order from 1 to threshold value, gas and heat energy are assumed to be endogenous variables, while electricity power and cold energy are assumed to be exogenous variables; during the autoregressive model order above threshold value, gas and heat energy are assumed to be endogenous variables, while only electricity power is assumed to be exogenous variables. Heat energy can be expressed as:

$$
l_{h}(t)=\left\{\begin{array}{l}
\left(\begin{array}{ll}
A_{1} & A_{2}
\end{array}\right)\left(\begin{array}{l}
L_{g} \\
L_{h}
\end{array}\right)+\left(\begin{array}{ll}
B_{1} & B_{2}
\end{array}\right)\left(\begin{array}{l}
l_{l}(t) \\
l_{c}(t)
\end{array}\right)+\varepsilon(t) \quad, 1 \leq t \leq 20, t=30 \\
\left(\begin{array}{ll}
A_{1} & \left.A_{2}\right) \\
L_{g}^{\prime} \\
L_{h}^{\prime}
\end{array}\right)+B_{l_{e}} l_{e}(t)+\varepsilon(t) \quad, 21 \leq t \leq 29
\end{array} .\right.
$$

\section{Analysis of the investment environment under the Incremental Distribution Reform of the Park}

Accurate load forecasting for industrial parks based on the VAR models can improve the investment decisionmaking ability of power grid enterprises. The impact of the liberalisation of the investment business of incremental distribution grids on the investment of grid enterprises is mainly in the following areas.

(1) Investment scale. After the liberalization of the incremental distribution business, the total amount of investment will change significantly after the introduction of competition, whether in the "stock area" or the "blank area". The new power grid reform will affect the investment in power grids, as it is difficult for grid enterprises to make a uniform investment in power grids as a whole. To achieve sustainable development of the company, it must be required to go to continuously raise funds and make investments in the power grid. Grid enterprises to raise funds should focus on investment risk, in the face of social capital competition, grid enterprises need to set a more reasonable cost management model, to avoid the total deviation of the investment scale is too large, affecting business operations.

(2) Investment benefits. Incremental distribution grid reform can revitalise some of the stock assets, thus improving the efficiency of the use of grid assets and reducing the duplication of grid construction and wasteful investment. However, for the stock area to launch the incremental distribution investment business, there will be multiple investment entities. However, according to the actual situation, the stock part of the distribution network operation is still responsible by the power grid enterprises, so that the cost in the case of not reduced, the stock of the incremental part still has a certain competition, making the power grid enterprises in this part of the benefit is affected, it is difficult to be guaranteed.

(3) Investment focus. Incremental distribution grid investment should be combined with local government development planning, land planning, industrial planning and other sciences in an organic way, which makes incremental distribution grid investment no longer a simple act of grid construction, but should be developed together with local gas supply, heating, distributed power supply, electric vehicles and other public services to meet all kinds of access needs.

(4) Investment risk. Under the traditional mechanism, the power grid company has monopoly in the distribution area, often in the investment without considering the economy, more concerned about the technicality, reliability improvement, but after the opening of the electricity sales side, the introduction of social capital competition, power grid enterprises can not be as before only focus on the technical aspects, but should be comprehensive consideration of economic benefits, the development of incremental area investment situation is complex, if not strengthen the risk analysis, and then incremental area investment benefits are not obvious, then it will bring resistance to the subsequent development of incremental distribution business and lose the first opportunity.

\section{System dynamics-based linkage of factors influencing grid investment}

Investment decisions in grid planning need to be analysed by incorporating multiple types of factors, and investment options are the result of the interaction and coordination of different factors. Therefore, the overall process of grid planning can be described as a dynamically evolving system with the following characteristics.

(1) There is not a single relationship between the various types of factors in grid investment, but rather an interaction and a chain of conduction feedback between them, and ultimately a multi-level chain feedback structure.

(2) In a dynamically evolving system, there are complex mechanisms of action based on a single linear feedback for each factor. In a particular situation, the feedback mechanism needs to be expressed through a combination of quantitative and qualitative models, a single model is 
difficult to meet the requirements of the formulation, the use of system dynamics of the model, the use of table functions and related equations can play a very good representation effect.

(3) In investment planning, the causal relationships between systems are not immediately apparent, and there is a certain lag in the impact of some variables on the whole system. In addition, the relative delays in information sharing, decision analysis and transmission processes of the participants in the investment decision will make the impact of different variables appear with different degrees of lag.

Total electricity demand can be made up of two components: the stock component and the incremental component. The power system reform document clearly proposes to liberalise the incremental distribution grid business, allowing social capital to enter and participate in market competition. The investment planning decision is based on the relationship between the planned investment capacity, the planned incremental assets of the grid enterprises and the actual planned investment capacity, and a system dynamics stack flow diagram is established.

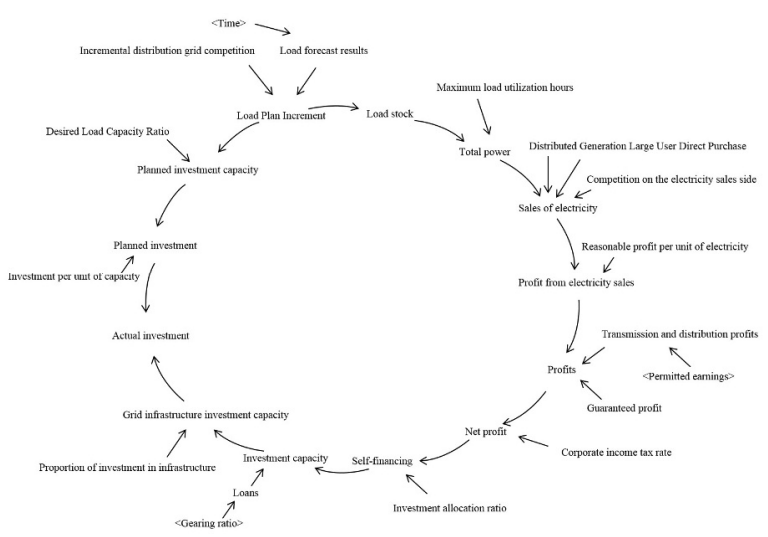

Figure 1. Feedback relationship for investment in the campus grid

\section{Analysis of the impact of grid investments in incremental distribution parks}

(1) the impact of the profit of the power grid company, after the reform of the power system, the total profit of the power grid company can be composed of three parts: one is the main business income, i.e. transmission and distribution profit, the profit model of the power grid is changed from the traditional purchase and sale price difference to the collection of over-grid fees; two is the guaranteed profit, the power grid needs to undertake the guaranteed power supply service of its power supply business area, mainly for the first production of agriculture and residential users; three is the establishment of power sales company after Power sales profits, the new situation, part of the electricity will be due to competition by other power sales body snatched, the power grid company set up by the power sales company can be directly negotiated with the power plant purchase price, sales side of a number of power sales company into, power sales company has the right to independent pricing, its sales price can be based on their own operating conditions and competitors' electricity price level to determine.

(2) Impact of investment situation. The impact of the grid company's actual investment in the previous year is divided into two main components: firstly, through the transfer to fixed assets, which affects transmission and distribution prices; and secondly, through meeting and improving the supply capacity, which affects the amount of electricity transferred. The impact of these two components ultimately affects the profit for the year. The realisation of this year's profit has a binding effect on the next year's investment plan. The actual investment each year affects the approved permitted return of the grid company through the transfer of fixed assets, and the approved permitted cost through the depreciation of fixed assets, which in turn affects the transmission and distribution price. As can be seen, the annual investment is ultimately recovered through the grid's transmission and distribution profits. However, the focus of the electricity market reform is to strictly control grid profits, so given the government's control actions, the actual investment of the grid company is not reflected in each year's transmission and distribution price; instead, it is gradually reflected in the next regulatory cycle through the accumulation of certain regulatory cycles. As a result, there is a cyclical delay in the recovery of investment.

\section{Concluding remarks}

This paper analyses the impact of the new situation on the investment efficiency of power grids from the aspects of load forecasting for industrial parks based on the VAR models, transmission and distribution price reform, electricity sales side market reform, incremental distribution grid reform and energy transformation and clean substitution, laying a theoretical foundation for the subsequent determination of the factors influencing the investment efficiency of power grid enterprises and the establishment of the model. In the context of the new situation, grid enterprises pay more attention to investment efficiency management, strive to improve the efficiency of asset utilization in their own operations, win market competitiveness, further optimize the investment structure and enhance the economic benefits of grid operations; in addition, grid enterprises also pay attention to the social and environmental benefits of project investment, ensure the safe and stable operation of the power system and power quality, while vigorously promoting large-scale centralized and distributed clean In addition, grid enterprises also focus on the social and environmental benefits of project investment, ensuring the safe and stable operation of the power system and power quality, while vigorously promoting large-scale centralized and distributed clean energy consumption. In terms of investment impact, the annual investment by grid companies is eventually recovered through the grid transmission and distribution profits. However, the focus of the electricity market reform is on strict control of grid 
profits, so given the government's control actions, the actual investment of grid companies is not reflected in the transmission and distribution prices of each year; instead, it is gradually reflected in the next regulatory cycle through the accumulation of certain regulatory cycles. As a result, there is a cyclical delay in the recovery of investment.

\section{Acknowledgments}

This work was supported by the Science and Technology Project of SGCC, Research on the competition situation and operation mode of distribution companies in the park (52170018000S).

\section{References}

1. Flexible block offers and a three-stage market clearing method for distribution-level electricity markets with grid limits[J]International Journal of Electrical Power and Energy Systems, 2021, 130.

2. Evaluation and Analysis of Total Factor Input and Output of Power Grid Enterprises under the New Situation[J]IOP Conference Series: Earth and Environmental Science, 2021, 680(1).

3. Research on Decentralized Trading Strategy of Electricity Market Based on Blockchain Technology[J]E3S Web of Conferences, 2020, 185

4. Regulating electricity distribution networks under technological and demand uncertainty[J]Energy Policy, 2020(prepublish)

5. Dynamic pricing in electricity and natural gas distribution networks: An EPEC model[J]Energy, 2020, 207

6. ADMM-based market clearing and optimal flexibility bidding of distribution-level flexibility market for day-ahead congestion management of distribution networks[J]International Journal of Electrical Power and Energy Systems, 2020, 123. 